\title{
Multisession Radiosurgery for Large Glomus Jugulare Tumors in and Around Jugular Foramen
}

\author{
Yoshihisa Kida* \\ Gamma Knife Center, Okuma Hospital, Nagoya, Japan
}

*Corresponding author: Yoshihisa Kida, Gamma Knife Center, Okuma Hospital, 2-9-

34, Ozone, Kitaku, Nagoya, Japan.

Published Date: April 14, 2021

\begin{abstract}
There are two cases of large glomus jugulare tumors growing in and around jugular foramen, and they were successfully treated with multisession gamma knife treatments. The tumors demonstrated remarkable shrinkage without any neurological deterioration and serious adverse effects. Since the surgical procedure may associate serious complications often, stereotactic radiosurgery seems to be a promising option.
\end{abstract}

Keywords: Chemodectoma; Gamma knife; Glomus tumor; Jugular foramen paraganglioma; Radiosurgery

\section{Introduction}

Glomus jugulare tumors are essentially benign, often growing in and around skull base and upper cervical portion. Jugular foramen is one of the main origin of this tumor, extending into petrous bone and causing the signs of cranial nerve impairments. They have tremendously rich vasculature and usually large in volume. Therefore, it is very difficult to successfully eradicate the whole tumor with single surgical intervention. Standard external or stereotactic irradiation has been reported as an alternative treatment in the past. This time, we have encountered two cases of very large or huge glomus tumors growing in and around jugular foramen and treated with multi-session gamma knife treatment.

\section{Clinical Cases and Methods}

After the our first report on radiosurgery glomus jugulare tumor with gamma knife [1], we have continued our efforts to manage this disease with it. Recently we have encountered two cases with large glomus tumor growing in and around jugular foramen, widely extending into petrous bone and to upper cervical portion. They have been treated with microsurgery before and referred to us for the purpose of radiosurgery.

\section{Case Study}

\section{Case I: 49-year-old lady}

Because of progressive hearing disturbance, she visited nearby hospital and diagnosis was made as skull base tumor. Just after arterial tumor embolozation, she underwent microsurgery via transmastoid approach with partial tumor resection. Then she received a first gamma knife treatment for residual tumor in another institution. Due to tumor progression nine years later, she was referred to our hospital. Neurologically she had a complete right hearing loss, facial palsy and bulbar palsy. Her MRI showed a large tumor in the right petrous bone extending medially and laterally from jugular foramen. Two additional sessions of gammaradiosurgery was planned and carried out with the 3 months interval (Table 1). The tumor showed a minor shrinkage thereafter and no significant progression of neurological deficits (Figure 1).

\section{Case II: 67-year-old man}

He developed left facial palsy and then presented with a sudden bleeding from the left ear, transferred to the emergency clinic. His 
MRI showed a huge tumor in the left skull base extending into upper cervical portion. With emergency surgery, a part of the skull base tumor, left parotid gland were removed. After the surgery, he has completely lost his left hearing. After 10 years, his MRI showed tremendous tumor regrowth in the same site. He underwent a second microsurgery with partial tumor resection again. After the operation, in addition to the hearing loss, he developed heft facial palsy, sensory disturbance of left face and tongue. He was transferred to our hospital for the purpose of gamma knife treatment.

Since there was a huge tumor growing in the petrous bone and extending to upper cervical portion, he has had the two-session radiosurgery, first for a large tumor in cerebello-pontine angle and then the tumor in petrous bone (Figure 2). Because of large tumor volume, each sessions were carried out by 5 fractionations as shown in the table (Table 2). The tumor showed a tremendous and continuous shrinkage without further neurological deterioration (Figure 3) except for a perifocal brain edema lasting for several months after the first session. He was able to return to his usual life thereafter. He still has a large tumor in the upper cervical portion, but just watch the course since it is not growing up.

Table 1: Dose planning of the case I: Three sessions of radiosurgery was performed with the marginal dose of 14 Gy. Target volumes of each session were 2.1, 6.97, $3.03 \mathrm{~cm}^{3}$ respectively. Three parts of tumor showed minor response during 26-123 months after the procedures.

\begin{tabular}{|c|c|c|c|c|}
\hline Site & Volume $\left(\mathbf{c m}^{\mathbf{3}}\right)$ & Marginal Dose (Gy) & Follow-up (month) & Response \\
\hline $1^{\text {st }}$ Juglar Foramen & 2.1 & 14 & 123 & Minor Response \\
\hline $2^{\text {nd }}$ Medial Pyramis & 6.97 & 14 & 26 & Minor Response \\
\hline $3^{\text {rd }}$ Lateral Pyramis & 3.03 & 14 & Minor Response \\
\hline
\end{tabular}

Table 2: Dose planning of the case II: Two large parts of tumor in cerebello-pontine angle $\left(14.46 \mathrm{~cm}^{3}\right)$ and pyramis $\left(19.7 \mathrm{~cm}^{3}\right)$ were treated with fractionated radiosurgery. Since a moderate perifocal edema occurred after the 1st treatment, the marginal dose for the second was reduced with the reference of BED. Each parts of tumor showed an excellent responses at 40 and 28 months later.

\begin{tabular}{|c|c|c|c|c|c|}
\hline Site & Volume $\left(\mathbf{c m}^{3}\right)$ & Marginal Dose (Gy) & BED (GyE) & Follow-up (month) & Response \\
\hline $1^{\text {st }}$ Cerebello-Pontine Angle & 14.46 & $\begin{array}{c}6.0 \times 5(\text { Equivalent to } \\
15.4 \mathrm{~Gy})\end{array}$ & $\begin{array}{c}\text { Acute } 75 \text { GyE Delayed } \\
120 \mathrm{GyE}\end{array}$ & $\begin{array}{c}40 \text { months } \\
\text { PR (Marked shrink- } \\
\text { age) }\end{array}$ \\
\hline $2^{\text {nd }}$ Pyramis Middle Fossa & 19.7 & $\begin{array}{c}5.0 \times 5(\text { Equivalent to } \\
13.2 \mathrm{~Gy})\end{array}$ & $\begin{array}{c}\text { Acute } 56.5 \mathrm{GyE} \text { Delayed } \\
87.5 \mathrm{GyE}\end{array}$ & $\begin{array}{c}28 \text { months } \\
\text { MR (Minor shrink- } \\
\text { age) }\end{array}$ \\
\hline
\end{tabular}
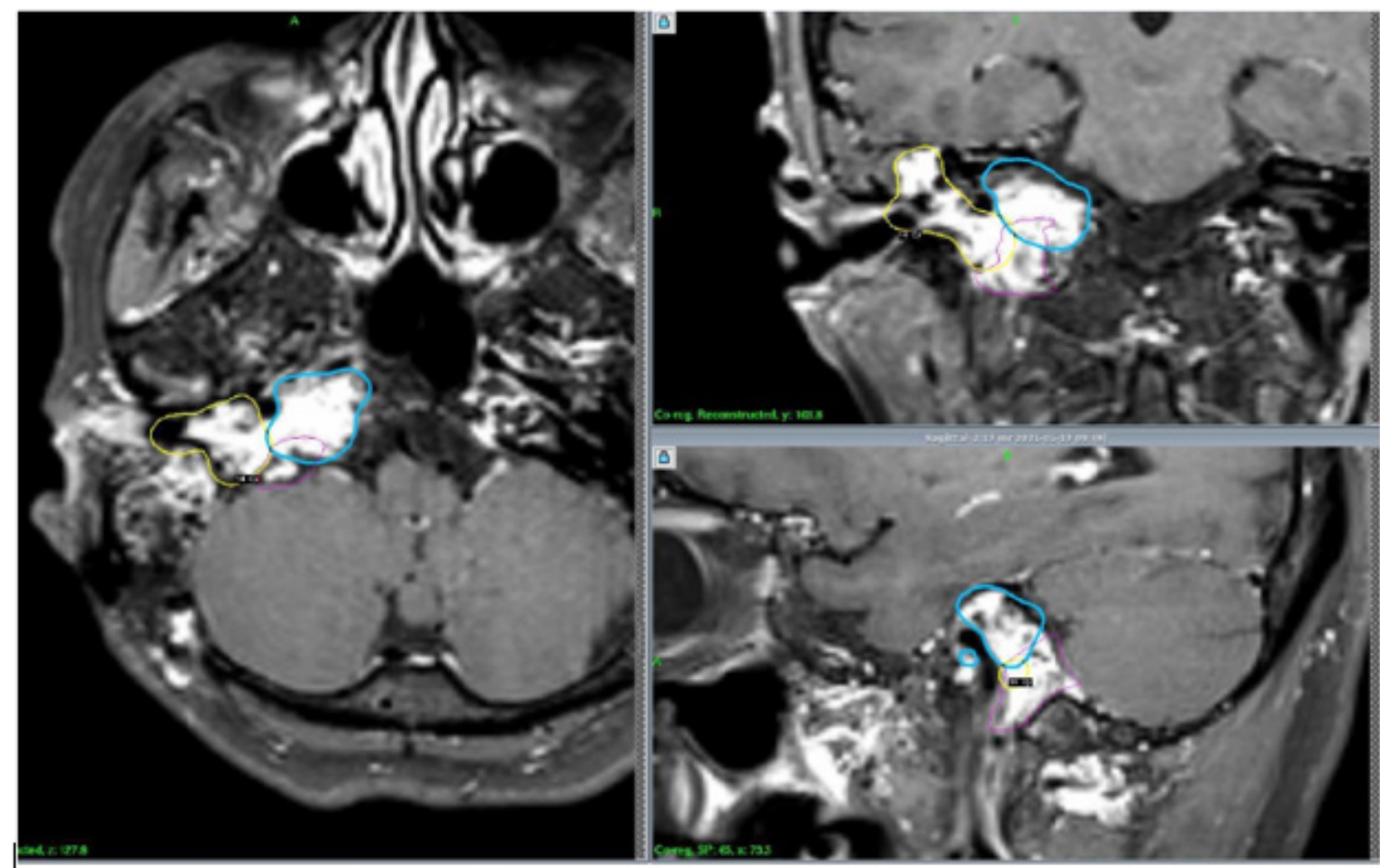

Figure 1: The tumor around jugular foramen were treated first and followed by radiosurgery for the tumors in the medial and lateral petrous bone. Note the shrinkage of the tumors when compared with the tumor size at radiosurgery. 1st session: green, 2nd session: blue, 3rd session: yellow. 

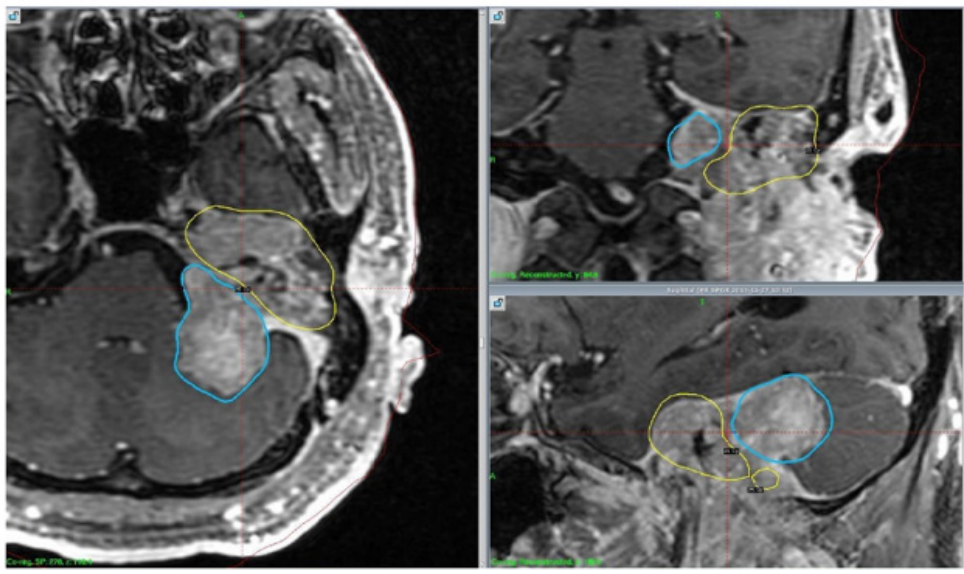

Figure 2: Case II: Large tumors in cerebello-pontine angle and skull base are shown. Blue and yellow lines demonstrate the margins of the tumor where the marginal dose of stereotactic irradiation were delivered by gamma knife.

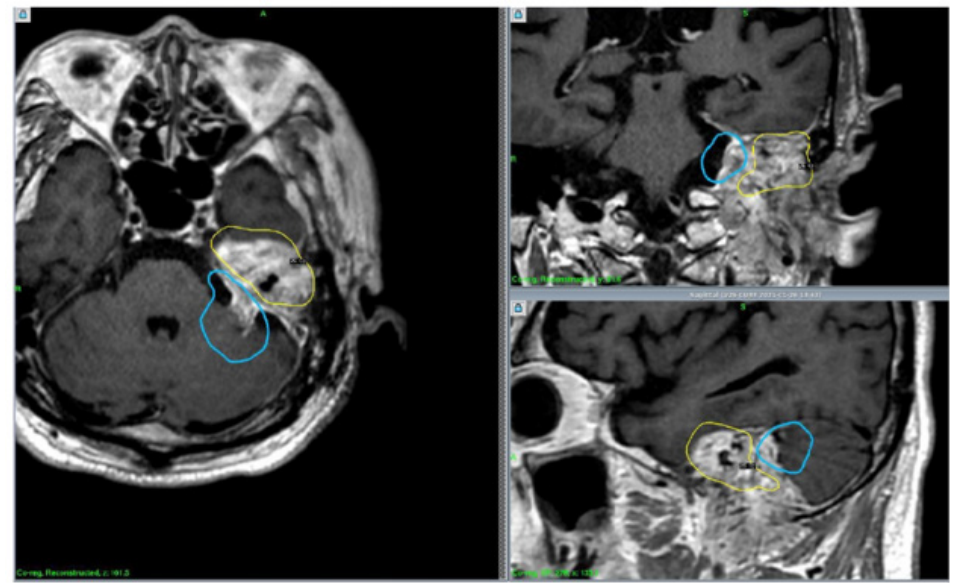

Figure 3: Case II: The tumors in cerebello-pontine angle and in the middle fossa showed a remarkable shrinkage after radiosurgery. But an apparent perifocal edema has been developed and lasted for several months. Note the tumor extending into the neck, which remains untreated.

\section{Discussion}

Although glomus jugular tumor is benign in character, microsurgery for glomus tumors in and around jugular foramen are very much troublesome because of the location as well as the associated rich vasculature. Hearing disturbance, disequilibrium and bulbar palsy are main and popular symptoms. Because of bulbar palsy, swallowing disturbance and ear bleeding, couples of otolaryngologists were involved for the treatment. Serious complications in association with the surgery, reportedly not rare including death [2]. Moreover, residual or recurrent tumors are not rare, which may require the further treatments. Currently various treatment options, including surgery, radiation therapy and endovascular procedures were reported [3-5].

After the promising reports of standard irradiation [6,7], several reports of stereotactic radiosurgery have been accomplished [1,812]. They demonstrated a successful tumor control as well as a long-term symptomatic stability in most of the cases, but the tumors were not so large and not fractionated in many of them.

Our two cases responded to radiosurgery nicely, and the tumors showed a remarkable shrinkage or standstill of growth without causing any symptomatic deterioration. Since one case still have residual and untreated tumor outside the cranium [5], he may require an additional treatment later on. Since the glomus jugulare tumors are large or huge when they are found, or even after microsurgery, they cannot be managed by only one procedure. Currently single session radiosurgery is performed only for relatively small tumors. Instead for large tumors, multi-session radiosurgery either volume-staged or dose staged, may be advisable chiefly because of safety. In addition to fractionation, careful dose selection employing the idea of BED (biological effective dose) may be required.

\section{Conclusion}

Two cases of large glomus tumors in the skull base are successfully treated with multi-session radiosurgery. Since glomus 
tumor is essentially benign and slow growing, fractionated or multisession radiosurgery is an excellent alternative in addition to surgery or to simple observation.

\section{Acknowledgement}

None.

\section{Conflict of Interest}

\section{No conflict of interest.}

\section{References}

1. Y Kida, T Kobayashi, T Tanaka, H Oyama (1995) A new strategy for the treatment of jugular foramen tumors using radiosurgery. No Shinkei Geka 23: 671-675.

2. Al Mefty 0, Teixeira A (2002) Complex tumors of the glomus jugulare: criteria, treatment and outcome. J Neurosurg 97: 1356-1366.

3. Brown JS (1985) Glomus jugulare tumors revisited: a ten-year statistical follow-up of 231 cases. Laryngoscope 95: 284-288.

4. Madison Michael, Robertson JH (2004) Glomus jugulare tumors: historical overview of the management of this disease. Neurosurg Focus 15: 17(2): E1.
5. Deng Q, Wang Y, Chen X, Zhou Q (2018) Case report of a rare gliomus jugulare tumor extended within the extracranial internal jugular vein: emphasis on initial ultrasound findings and literature review. Med Ultrason 1(1):111-113.

6. Cole JM (1977) Glomus jugulare tumor. Laryngoscope 87: 1244-1258.

7. Ogura JH, Spector GJ, Gado M (1978) Glomus jugulare and vagale. Ann Otol Rhinol Laryngol 87: 622-629.

8. Gordon Li, Chang S, Adler JR, Lim M (2007) Irradiation of glomus jugulare tumors: a historical perspective. Neurosurg Focus 23: E13.

9. Gerosa M, Visca A, Rizzo P, Foroni R, Nicolato A, et al. (2006) Glomus jugulare tumors: The option of gamma knife radiosurgery. Neurosurgery 59: 561-569.

10. Guss ZD, Batra S, Li G, Chang SD, Parsa AT, et al. (2009) Radiosurgery for glomus jugulare: history and recent progress. Neurosurg Focus 27: E5.

11. Guss ZD, Batra S, Limb CJ, Sughrue ME, Redmond K, et al. (2011) Radiosurgery of glomus jugulare tumors: a meta-analysis. Int J Radiat Oncol Biol Phys 81(4): e497-502.

12. Sahyouni R, Mahhoubi H, Moshtaghi O, GoshtasbiK, Sahyouni S, et al. (2018) Radiosurgery of glomus tumors of temporal bone: a metaanalysis. Oto Neurootol 39: 488-493. 